\title{
HANRYU SWEEPS EAST ASIA
}

\author{
How Winter Sonata is Gripping Japan
}

\section{Toru Hanaki, Arvind Singhal, Min Wha Han, Do Kyun Kim and Ketan Chitnis}

\begin{abstract}
The present article analyzes the popularity of Winter Sonata (a South Korean television series) among Japanese audiences, especially among middle-aged women, and the impact of the accompanying hanryu phenomenon (the current fad for every aspect of South Korean popular culture) on Japanese society. Various types of primary and archival data were collected including indepth qualitative interview surveys from 33 female Japanese viewers of Winter Sonata. The interpretive analysis of the data reveals the reasons for Winter Sonata's popularity in Japan, and how this television drama and the hanryu phenomenon have influenced Japanese perceptions of Korean residents living in Japan, South Koreans and North Koreans. In light of the troubled historical relationship between Japan and Korea (given Japan had colonized the Korean peninsula for several decades), the impact of Winter Sonata and the hanryu phenomenon is especially noteworthy.
\end{abstract}

Keywords / hanryu (Korean wave), interpretive analysis, Japanese audience, social influence, South Korea, television drama, Winter Sonata

Hanryu (literally 'Korean wave'), referring to the current fad for all aspects of South Korean popular culture - movies, music, online games, hip-hop clothes, hairstyles and cosmetics - is sweeping across East Asia like a cultural tsunami (Dator and Seo, 2004; Endo and Matsumoto, 2004; Seo, 2005). By early 2006, several countries Japan, Taiwan, Mongolia, Hong Kong, Uzbekistan, Thailand, Malaysia, Vietnam and the People's Republic of China - were in hanryu's grip (Onishi, 2005a). Interestingly, this Korean 'soft cultural power' has especially taken hold in Japan, the country that annexed and colonized the Korean peninsula through 'hard military power' some 95 years ago.

Video rental shops and bookstores in large Japanese cities such as Tokyo, Osaka, Nagoya and Kobe now have exclusive sections dedicated to South Korean films, television programs, magazines and books (Tsukahara, 2004; Yoshida, 2004). Japanese department stores and clothing boutiques exclusively feature South Korean cosmetics, clothes and jewelry. Korean-language schools have proliferated in Japan, and the audience for NHK's Korean-language instruction program has doubled in the past few years (Demick, 2005). Membership at Rakuen Korea, a matchmaking service for Japanese and Koreans with offices in Seoul and Tokyo, has risen sharply 
(Wiseman, 2004). South Korean actors, rock stars and models have acquired 'star' status in the Japanese mass media. Korean restaurants in Japan have begun to attract a large number of customers. Travel to South Korea has become common (Endo and Matsumoto, 2004; 'Travel Agencies Cashing in', 2004). Japanese homemakers now exchange recipes for kimchi, a popular Korean fermented pickle. This popular craze for all South Korean cultural products is called hanryu.

The hanryu phenomenon began to tighten its grip in Japan around 2003, when the 20-hour, 20-episode South Korean television series Winter Sonata was broadcast in Japan. Since NHK, Japan's national network television, first broadcast Winter Sonata in 2003 on its satellite channel (it has subsequently been broadcast nationwide several times), it achieved immense popularity among Japanese audiences, and especially among Japanese middle-aged women (Endo and Matsumoto, 2004; Murakami, 2004; 'War Torn', 2004). Winter Sonata's unprecedented popularity opened the floodgates for the Korean tsunami to wash ashore in Japan.

The purpose of the present article is to analyze the popularity of Winter Sonata among Japanese audiences, especially among middle-aged women, and to investigate how the hanryu phenomenon has influenced Japanese audiences' perceptions of Korean residents in Japan, and of South and North Koreans. A description of Winter Sonata, including its storyline, is provided along with the historical context of political and people-to-people relations between Japan and Korea, especially since the Second World War. Our key research questions are posed, our method and data collection procedures are described, the study's research results are presented, and implications and conclusions are drawn.

\section{Background to Winter Sonata}

Winter Sonata, a television drama series, was produced by the Korean Broadcasting System (KBS) and first broadcast in South Korea in 2002. Directed by Yoon Seok-ho, perhaps the most respected South Korean television drama producer-director, Winter Sonata was first broadcast in Japan in 2003 on the NHK satellite channel, NHK BS2 (Murakami, 2004; Victoria, 2005). Because NHK BS2 requires the viewers to purchase special devices and pay subscription fees, the number of viewers in the first run was limited. Nevertheless, the broadcast of Winter Sonata on NHK BS2 received much acclaim, leading to the rerun of the drama on the same satellite channel later in 2003. Goaded by surging audience demand, NHK broadcast Winter Sonata, from April to August 2004, on the NHK general channel (with the widest nationwide reach) during the late evening slot - usually reserved for popular Hollywood programs (Victoria, 2005). Further, the uncut version of Winter Sonata in Korean language with Japanese subtitles was broadcast in late December 2004 on NHK BS2.

Winter Sonata is a love story between a male character, Jun-sang, and a female character, Yu-jin, who fall in love (both for the first time) at high school (see Kim, 2006). However, Jun-sang has to leave for the US to pursue higher education, and prior to his departure, he and Yu-jin arrange to meet at a specified location on New Year's Eve. Yu-jin keeps waiting but Jun-sang never appears. The next day, Yu-jin learns that Jun-sang was killed in a road accident, on his way to meet her. Yu-jin is 
devastated; she has lost her first love. Fifteen years later, Jun-sang reappears in front of Yu-jin but now his name is Min-hyung. Jun-sang does not recognize Yu-jin because he lost his memory in the road accident. Although Yu-jin believes that Jun-sang is dead, Min-hyung's resemblance to Jun-sang and Yu-jin's memory of her first love lead the two to fall in love with each other again. After facing many difficulties, in the last episode, Jun-sang and Yu-jin meet at the house that Jun-sang designed as an architect. By this time, Jun-sang is almost blind. He lost his sight in a second road accident, but the trauma has somehow restored his lost memory. In the moving last scene, Jun-sang and Yu-jin recognize each other. Their first love is consummated.

The story of Winter Sonata was a complicated one; it was not a straightforward love story as this brief description might suggest. Similar to many other South Korean dramas, an intricate web of family relationships complicates the plot, and a sense of mystery sustains audience attention. For instance, Jun-sang transferred to the high school where he meets Yu-jin with the primary intention of finding his real father. At a certain point in the story, the drama leads the audience to suspect that Jun-sang's father and Yu-jin's father might be one and the same person, and so the two lovers might be siblings. As the tale unfolds, the intricate web of family ties is untangled, resulting in a sense of mystery that dramatizes the main story of pure love between Jung-sang and Yu-jin.

Winter Sonata became extremely popular among Japanese audiences, especially among Japanese middle-aged women. Those women were attracted to Bae Yong-joon, a baby-faced South Korean actor in his early thirties, who played the main character (Jun-sang) in the series. When Bae visited Tokyo in 2004, some 3500 Japanese women in their forties, fifties and sixties gathered at Narita Airport to welcome him. A contingent of 350 riot police controlled the frenzied crowd. In the pushing and shoving that ensued to catch a glimpse of Bae, 10 women had to be taken to hospital by ambulance for fractures, bruises and sprains (Onishi, 2004; Victoria, 2005).

Many of these Japanese middle-aged women traveled to South Korea to visit the location sites of Winter Sonata on package tours provided by major Japanese travel agencies, such as JTB and Kinki Nippon Tourist (Demick, 2005; Endo and Matsumoto, 2004; 'Travel Agencies Cash in', 2004). The Seoul Plaza Hotel, where Bae stayed as part of the drama's plot, once had a month-long waiting list for that particular suite. Posters, calendars and books of photographs of Bae retailed for up to US\$150. Many of the Japanese middle-aged women downloaded pictures of Bae on their cell phones, checked his Japanese-language website daily and could recite with confidence his daily diet and exercise regimen (Wiseman, 2004). Hyundai Research Institute, an economic forecasting firm based in Seoul, estimated that the Bae phenomenon, riding the crest of hanryu, produced a US\$4 billion dollar increase in business between South Korea and Japan (Demick, 2005). ${ }^{1}$

\section{Troubled Historical Relations between Japan and Korea}

The massive popularity of Bae Yong-joon, Winter Sonata and everything South Korean is astounding considering the historical relations between Japan and South 
Korea. The region currently called Japan and the region currently called South Korea have exchanged people, foods, products and knowledge for more than 1000 years. However, the relationship became increasingly hostile starting around 1910 when Japan annexed the entire Korean Peninsula (Dudden, 2005). Japan continued its rule over the Korean Peninsula until 1945, when it surrendered fully to the Allied Forces, marking the end of the Second World War. The region south of latitude 38 in the Korean Peninsula came under the control of the US, while the region north of the latitude 38 came under the control of the Soviet Union. In 1948, the Republic of Korea (South Korea) and the Democratic People's Republic of Korea (North Korea) were established in the southern region and the northern region of the peninsula, respectively. Although the Korean Peninsula might seem to be clearly divided into the Communist north and the democratic south from a western perspective, the division is neither that clear nor voluntary among Koreans (Oberdorfer, 2001).

This complex historical past has cast a dark shadow on postwar relations between Japan and South Korea. For instance, Japanese and South Korean governments continue to dispute territorial rights over an island (Takeshima in Japanese and Dokdo in Korean) in the sea between the two countries (Endo and Matsumoto, 2004). Japanese and South Korean historians have argued over the portrayal of their shared historical facts, especially about Japanese military atrocities during the Second World War. Former Korean 'comfort women', brutally forced into sexual labor for Japanese military officers during the war, have sought apologies and compensation from the Japanese government, but in vain. Further, the Japanese annexation of the Korean Peninsula led to non-voluntary exportation of Korean slave laborers to Japan. Many of their descendants, estimated at about 700,000, still live in Japan without Japanese citizenship. Those descendants of Korean immigrants are called Zainichi Korean (literally 'Korean residents in Japan').

For such historical reasons, the relationship between the Japanese people (especially those who are older) and the South Koreans, North Koreans and Zainichi Koreans is highly strained. Chung (1995) found that the public discourse within Japanese society treated Koreans as people who are dirty, emotional and dangerous. The younger generation in Japan, relatively speaking, are more open toward the Korean people than the older generations, in large part because they feel a sense of distance with past events, and also because history textbooks in Japan are relatively silent on Japan's wartime atrocities on the Korean Peninsula. In recent years, since former South Korean president Kim Dae-jung proclaimed an open and amicable policy toward Japan, the political and people-to-people interactions between the South Koreans and the Japanese increased in frequency, tempering the historical animosity to a certain extent.

When Winter Sonata was broadcast in Japan, it was not devoid of the historical baggage carried by Korea and Japan. Thus its popularity among Japanese audiences, especially middle-aged women, many of whom presumably cherished negative sentiments toward Koreans, was even more surprising. It is these Japanese women who now worship South Korean actor Bae Yong-joon, enroll in Korean language schools and plan pleasure trips to visit sites in South Korea where Winter Sonata was shot. 
In light of the preceding discussion, our present research centered around three research questions:

Research Question 1: What explains the popularity of Winter Sonata among Japanese audiences, especially among middle-aged women?

Research Question 2: How have Winter Sonata and the accompanying hanryu phenomenon changed the Japanese women's perceptions of Zainichi Koreans, South Koreans and North Koreans?

Research Question 3: How have Winter Sonata and the accompanying hanryu phenomenon influenced the everyday behaviors of Japanese women?

\section{Data Collection}

The present research team, which includes a Japanese national, a South Korean national, a Zainichi Korean and others, collected multiple types of data during 2005. We read over 100 articles covering Winter Sonata and the hanryu phenomenon in major newspapers, magazines and websites from Japan, South Korea, the US and some other East Asian countries. Two of the authors directly observed the rise of the hanryu phenomenon in Japan, and on summer and winter break trips home, conducted about a dozen in-depth interviews with Japanese and Zainichi Koreans who had watched Winter Sonata. We also conducted an extensive in-depth interview, over several sessions, with one middle-aged Japanese woman in the US, who was an avid fan of Winter Sonata. This respondent collected and filed numerous media clippings about the program, went on a tour of South Korea with her friend and the friend's mother, stayed in the same suite in the Seoul Plaza Hotel where Bae Yong-joon had stayed and visited several sites - such as the Yong Pyong Ski Resort and Choon-cheon - where Winter Sonata was shot. Consumer products featuring Winter Sonata, such as its DVD, its soundtrack, as well as a replica of the necklace that Yu-jin wore in the drama, were collected to experience first hand the popularity of this phenomenon. About half-a-dozen Japanese documentary programs on Winter Sonata and the hanryu phenomenon were also examined.

While all of these data helped in contextualizing our analysis, this article particularly draws upon a written qualitative survey questionnaire that we administered to 33 female Japanese viewers of Winter Sonata in Japan. A qualitative analysis is particularly effective in obtaining a rich and in-depth understanding of the research phenomenon (Patton, 2002). The age of these 33 respondents ranged from 20 to 58 years. Among them, 18 respondents were in their fifties, six were in their forties, two were in their thirties and seven were in their twenties. Six of the respondents identified themselves as homemakers. Occupations of the others included a piano instructor, a private school teacher, a private school owner, a dance instructor, an ESL (English as a second language) teacher, an administrator, a corporate employee, a civil servant, a nurse and several students. The present researchers sent an openended survey questionnaire in the Japanese language, revolving around the three research questions, via regular mail and/or email to personal and professional acquaintances, who then distributed the surveys to avid viewers of Winter Sonata. 
All the questionnaires were returned to the present authors with written responses provided in Japanese. After one of the authors translated the responses into English, the team asked two fluent bilingual individuals to translate the English responses back into Japanese. This process confirmed that the essential meanings of the original Japanese responses were retained in the English translation. One of the authors, a Japanese national, conducted the first round of interpretive analysis of the responses, carefully reading the responses many times and identifying themes pertaining to each of the research questions (Patton, 2002). Then, the other authors examined the results of the interpretive analysis, refining the thematic analysis over several iterations.

\section{Winter Sonata's Popularity}

Research Question 1 asked: What explains the popularity of Winter Sonata among Japanese audiences, especially among middle-aged women? Our analysis identified four recurring, mutually non-exclusive thematic reasons for the popularity of Winter Sonata: (1) a heart-warming depiction of 'pure love', (2) the overall esthetic and poetic beauty of the television series, (3) the character portrayals that resonated with traditional Japanese values and (4) a sense of nostalgia for the past and a longing for a life that was not to be.

\section{Depiction of 'Pure Love'}

Most respondents noted the portrayal of 'pure love' as being the major narrative appeal of Winter Sonata. Unlike most Hollywood movies, and contemporary Japanese films and television dramas, Winter Sonata included no overt scenes of sex or passionate lovemaking. Instead, the television series depicted nuanced exchanges of 'pure' feelings. For instance, according to our respondents, one of the most memorable scenes of the drama was a depiction of the first date between Jun-sang and Yu-jin, who skip a high school class to be together by a lake. They make miniature snow figures, and to show his love for Yu-jin, Jun-sang makes his little snowman kiss her miniature snowwoman. While melodious music signifies romance, Yu-jin responds by kissing Jun-sang's cheek. After a moment of surprise, Jun-sang then gently puts his lips on Yu-jin's. Winter Sonata was filled with such symbolisms. Japanese middle-aged women were particularly attracted by these subtle descriptions of 'pure love', a counter to explicit sexual portrayals of affection. A homemaker in her forties commented, 'In contemporary Japan, "pure love" is no longer attractive to people and love is equated with a steaming physical relationship. A drama of "pure love", Winter Sonata, was refreshing.

\section{Esthetic and Poetic Beauty}

Our respondents noted that esthetic and poetic beauty strengthened the 'pure' quality of Winter Sonata. The drama featured several beautiful locations in South Korea, including a ski resort, a beautiful island and a beach. Further, Winter Sonata 
employed a variety of slow-paced, melodious music, conveying different moods and feelings. The music was especially loved by middle-aged Japanese women, who do not care much for the fast-paced, upbeat music of contemporary Japanese television dramas and Hollywood movies. In addition to the beautiful visual images and sounds, Winter Sonata is filled with memorable lines of dialogue. Many of our respondents could recite with ease dialogs such as 'You should not need a reason if you truly love a person', 'I will be your guiding star,' and 'the most beautiful house is the one built in one's heart'. The story moves and develops slowly, allowing the viewers to enjoy the lyrical stoicism. While some of our younger respondents in their twenties were occasionally bored with the slow development of the story, the relatively older respondents appreciated the moderate, non-hurried pace, allowing them to appreciate and savor the esthetic and poetic beauty.

\section{Resonance with Character Portrayals}

The characters of Winter Sonata evoked a strong sense of compassion and identification among Japanese middle-aged women. The following comment from a Japanese woman in her fifties is illustrative:

Above all, the popularity [of Winter Sonata] is because of the appeal of the actors and actresses. Attractive actors and actresses who completely absorb us do not exist in contemporary Japan. I want to watch enthralling orthodox handsome men and beautiful women on the television and movie screens, not boys and girls just around there. Japanese society has been greatly disrupted by sissy men and shameless women who proudly use masculine language. I am relieved to see manly men and womanly women in South Korean dramas.

As evident in this remark, the characters in Winter Sonata embodied the traditional gender values that Japanese middle-aged women have cherished since their youth.

The male main character, Jun-sang, was most popular among our respondents, followed by the female protagonist, Yu-jin. For Japanese middle-aged women, Junsang possessed the ideal male characteristics such as kindness, grace, morality, calmness and intelligence. A woman in her fifties, who owns a private school, expressed a strong affection for Jun-sang:

Jun-sang (later Min-Hyung) is my favorite. His facial expression was as melancholy as a high school student. . . His smile when he first met Yu-jin at his office was memorable as was his facial expression with his eyes closed when he spent a night by a fireplace in a snow mountain. All of them were attractive. Throughout the drama, Jun-sang, played by Bae Yong-joon, was a wonderful person with a very attractive smile.

The detailed way this respondent discusses Jun-sang resembles how a young women would discuss her cherished soul mate. In fact, this respondent openly noted that she felt jealous of Yu-jin when she received a necklace hidden in a snowball from Junsang in Winter Sonata. Most of the respondents shared their romantic affection for Jun-sang and the actor Bae Yong-joon. At the same time, quite a few respondents identified with Yu-jin's straightforward love for Jun-sang and her commitment to her own career. 


\section{Nostalgia and Longing}

The subtle depiction of pure love, overall esthetic and poetic beauty and endearing characters with traditional values evoked a sense of nostalgia among Japanese middle-aged women. A private school teacher commented:

The drama showed, in front of my eyes, a memory of pure love that I was about to forget. The freshness of the drama overlapped with my memory. They [the characters] never rushed but enjoyed the exchange of feelings while maintaining a certain distance. That kind of progress might be rejected as out of date in contemporary Japan. However, the slow pace especially matched the pace of our hearts. ... The drama reminded us of the heart of a young girl that we had before. I envisioned myself in the characters. The drama brought me back to the unfinished romance.

Most of our other women respondents also stated that Winter Sonata touched upon their nostalgia for an imagined past and a yearning for an emotional connection that they did not find in their personal lives. In essence, these women were creating in fantasy what they were missing in reality. This involvement allowed them to reminisce about what might have been with their old flames from their youths (Onishi, 2004; Wiseman, 2004). One respondent noted, 'Jun-sang is an ideal man. Sweet, intelligent, polite, and supportive. . . . I wish I could be Yu-Jin, I wish I could have his love.'

For our women respondents, Winter Sonata was similar to the old Japanese television dramas that they enjoyed in the 1960s and 1970s when they were growing up. Not surprisingly, the director of Winter Sonata is an avid admirer of old Japanese dramas. In any event, Winter Sonata reminded Japanese middle-aged women of their longings and nostalgia for their school days and resonated with the slow-paced Japanese television dramas of those times. As a woman instructor in her fifties indicated, Japanese middle-aged women are often treated merely as obasan (old woman), and Winter Sonata satisfied their hidden desire to be treated kindly and with love as when they were young.

\section{Changing Perceptions of Koreans}

Research Question 2 asked: How have Winter Sonata and the accompanying hanryu phenomenon changed Japanese women's perceptions of Zainichi Koreans, South Koreas and North Koreans? Winter Sonata influenced our respondents' perceptions of these three groups in various ways.

Some respondents unequivocally stated that their perceptions of Zainichi Koreans have not changed much by their watching Winter Sonata and the hanryu phenomenon; they were positive even before watching the television series in large measure because they had personal friends who were Zainichi Koreans. A teacher in her fifties commented, 'My perception toward Zainichi Koreans has not changed. My close friend is a Zainichi Korean and I have felt no discomfort toward them.' On the other hand, several respondents revealed that they had a sense of prejudice against the Zainichi Koreans, and Winter Sonata provided them with an opportunity to understand them better and feel emotionally closer to them. The owner of a private school confessed: 
I had had a sort of hatred toward Zainichi Koreans in Japan until that time. But after watching Winter Sonata, I felt like the feeling of hatred weakened to a certain degree, if not absolutely. I began to feel closer to them and became interested in talking to them.

As one of the young respondents in her early twenties commented, she hoped the Korean wave might have led Japanese people who had a negative perception of Zainichi Koreans to 'take off the historical glasses and look at the present with bare eyes'.

Many respondents stated that their perceptions of South Koreans became quite positive after watching Winter Sonata. South Korea is perceived by most Japanese as 'a country that is geographically close but psychologically far'. Winter Sonata provided the Japanese respondents with an opportunity to take a closer look at this 'psychologically far' neighboring country and to become more familiar with its landscapes, habits and everyday lives. A corporate employee in her fifties revealed:

Although South Korea is a neighboring country, I did not try to know the country, and I even looked down on it. Now I want to know South Korea and try to know South Korea. A country that is geographically close but psychologically far became a country that is both geographically and psychologically close.

Winter Sonata led many of the respondents to recognize the cultural commonalties between Japan and South Korea, such as respect for family, kinship networks and the elderly. Those values corresponded with Japanese traditional values that our middle-aged Japanese respondents admired (and may have weakened among the younger generation of Japanese).

As the Japanese mass media keeps broadcasting the threat of missile attacks by North Korea and the political/private attempts to reclaim abducted Japanese citizens from the country (Hirama and Sugita, 2003), our respondents' perceptions of North Korea have remained negative regardless of their watching Winter Sonata. The respondents described North Korea as 'dark', 'poor', 'difficult to understand', 'not free' and 'threatening'. They made a sharp distinction between South Korea and North Korea, and connected the hanryu phenomenon exclusively to South Korea. A corporate employee in her late forties represents the general sentiments of the Japanese respondents: 'North Koreans have different thoughts and standards of judgment. I cannot accept them as a country although I might be able to accept them as people.'

\section{Influencing Everyday Behaviors}

Research Question 3 asked: How have Winter Sonata and the accompanying hanryu phenomenon influenced the everyday behaviors of Japanese women? Winter Sonata and the hanryu phenomenon ignited by the television series strongly influenced the everyday behaviors of several of our respondents. Our respondents stated that on a daily basis they have begun to watch other South Korean television dramas, although prior to Winter Sonata being broadcasts, they were not interested in watching television dramas, including Japanese ones. Some respondents imported South Korean DVDs directly from South Korea and bought a universal, region-free DVD player to watch them (DVDs in Japan and South Korea use different encoding 
systems). This response from our women viewers is noteworthy given most Japanese middle-aged women do not consider themselves as ready adopters and users of such electronic devices. Many of the respondents noted that they have begun to incorporate more South Korean foods in their daily diet regimens. A homemaker in her early fifties stated:

After watching Winter Sonata, I became very interested in South Korean dramas. I watched several South Korean dramas, such as First Love, Images of Love (True to Love), and Hotelier, mainly the ones starring Bae Yong-joon, on video. I started to pay attention to South Korean sections of TV schedules. I began to to eat Korean seaweed, barbecue and kimchi.

Several of our respondents developed and/or increased their interests in various aspects of South Korean life. Many of them became interested in learning the Korean language and some reported enrolling onto courses through the televised NHK Korean conversation program and/or by attending a language school. A university student in her early fifties commented:

My interest in South Korea has multiplied. My interest has now expanded beyond South Korea to China and other Asian countries. I am enthusiastically learning Korean and Chinese languages, as well as the people, culture, economy, and politics of those countries in the College of International Relations at my university. About the recently discussed issues of different historical perceptions between Japan, South Korea and China, I think that I need to know the true history. I have begun to read a variety of books on the issue.

Winter Sonata fuelled the interest of its Japanese viewers to learn more about South Korea (and other Asian countries) and led them to actually take action. A number of respondents revealed that they had traveled to South Korea and visited the location sites of Winter Sonata. While many of them traveled on a package tour arranged by one of the major Japanese tourist companies, some respondents traveled independently.

An instructor in her late fifties, an administrator in her late forties and the administrator's mother traveled together to South Korea without their husbands and stayed in the same Seoul Plaza Hotel where Jun-sang stayed in Winter Sonata. They brought back canned coffee from the same store in Choon-cheon, where YuJin bought her coffee in the television series. Through such intense involvement in memorializing the characters, locations and products of Winter Sonata, an increasing number of Japanese people have now become familiar with the people and culture of South Korea.

\section{Discussions and Conclusions}

Our analysis suggests that the South Korean television series Winter Sonata became popular among Japanese audiences, especially among Japanese middle-aged women, mainly because of the drama's depiction of pure love, its overall esthetic and poetic beauty, its portrayal of characters with traditional values, and the nostalgia it evoked about their longings and feelings when they were young. These traditional values no longer find much play in mainstream Japanese popular media, which is inundated with Hollywood films and television programs. 
Our study also suggests that Japanese viewers' perceptions of Zainichi Koreans and South Koreans have generally become more positive, despite the historical baggage, because Winter Sonata enabled the viewers to become familiar with the people, culture, language, fashions and other aspects of South Korea. On the other hand, the viewers' perceptions of North Korea have remained negative even after watching Winter Sonata, largely because of the constant media coverage of the country as a potential military threat.

Our analysis further suggests that the experience of watching Winter Sonata led Japanese viewers to embark on several new daily habits, such as watching other South Korean television dramas, eating Korean food, learning the Korean language, buying Korean products and traveling to South Korea on package tours.

Some exceptions do exist for the overall response patterns described here. Several respondents, especially the younger ones, were not so enthralled by Winter Sonata; it was too slow and old-fashioned for their tastes. Consequently, the television drama did not alter their perceptions of Koreans or their everyday behaviors. Further, several respondents were already personally familiar with Zainichi Koreans and South Koreans, and therefore had no negative sentiments (or little historical baggage) toward them prior to watching Winter Sonata. Regardless of those exceptions, Winter Sonata and the hanryu phenomenon in general seem to have led the Japanese viewers to open their minds and develop empathic interests in Koreans (at least for the Zainichi Koreans and South Koreans). Over a period, such increased interest in Korean matters might stimulate Japanese people to overcome the negative legacy of their historical relationship with Korean people. A university student in her early twenties hoped so:

South Korea and North Korea are my neighbors. Although they are such close countries, Korean dramas and movies have just begun to spread among Japanese. I cannot help realizing that the shared history is such a deep-rooted issue between Japan and the two countries. However, I think that this hanryu phenomenon is a big change. Japan has never showed such a peaceful interest in Koreans before. If Japanese are able to maintain this welcoming, friendly heart toward South Koreans and North Koreans, this wave will become a great opportunity for restoring international relationships.

At the same time, critics believe, and perhaps for the right reasons, that the hanryu phenomenon is a mere creation of the mass media, including NHK and Japanese tabloid newspapers, and has little effect on Japanese national sentiments toward Koreans (Yong-sung, 2005). Others strongly believe that the popularity of South Korean dramas appeals only to a popular sense of reality ('To Keep "Hallyu" Going', 2005), and would not necessarily motivate the Japanese government to address the political and historical grievances of the Korean people. Further, an antihanryu phenomenon has emerged in reaction to the spread of the Korean wave, as represented by the Japanese comic book Hating the Korean Wave (Onishi, 2005b). The next few years will see how much Winter Sonata and the hanryu phenomenon actually contribute to the mutual understanding between Japanese and Koreans (i.e. Zainichi Koreans, South Koreans and North Koreans).

While this study answered several questions regarding Winter Sonata and the hanryu phenomenon, other questions remain to be answered by future research. 
For instance, future research should strive to understand how Zainichi Koreans, South Koreans and potentially North Koreans themselves interpret the hanryu phenomenon in Japan, to provide a more comprehensive view of this complex phenomenon. Further, as stated at the beginning of this article, the hanryu phenomenon has been spreading into other Asian countries, such as Taiwan, Mongolia, Hong Kong, Uzbekistan, Thailand, Malaysia, Vietnam and mainland China (Onishi, 2005a). Future research needs to investigate what qualities of Winter Sonata allowed this South Korean drama to diffuse to such culturally diverse countries, and what kinds of prosocial (or antisocial) influence the televised drama has exerted (see Singhal and Udornpim, 1997; Udornpim and Singhal, 1999).

The Japanese population and mass media have a tendency to become collectively and intensively excited about certain trendy issues (e.g. the Seoul Olympic Games in 1988, the World Cup Soccer Championship co-hosted by Japan and South Korea in 2004) for a short period of time, and soon after forget about the fever as though nothing has happened. For those characteristically capricious Japanese, Winter Sonata might have become an old story. However, the heritage of Winter Sonata is evident in many aspects of contemporary Japanese society. Other popular South Korean television dramas such as All In and Beautiful Days (Penn, 2004; Tsukahara, 2004) have become regular fare on Japanese television channels. Japanese newspapers and magazines have begun to routinely report South Korean entertainment news. South Korean popular culture has become a part of Japanese everyday life, and Winter Sonata seemed to have clearly played a role in getting the ball rolling.

Where will this Korean cultural wave end?

\section{Notes}

We thank the following individuals in Japan and the US who helped us in implementing the present research project: Ayako Deguchi, Michiko Ishinabe, Professor Motoko Nagao, Yukiko Goto, Chizuko Hanaki, Yoshiko Kasai, Keiko Mae, Eriko Mishima, Kohei Moritani, Chizuko Sengoku and Azusa Yamaguchi. This article is part of a larger, ongoing research project that looks at the influence of Winter Sonata among Japanese, Korean and Zainichi Korean viewers.

1. Such specific aggregate claims about increase in trade are hard to fathom and fully verify. Also, attribution of this increase in trade solely to hanryu and the popularity of Bae may be somewhat tenuous. Exact figures notwithstanding, hanryu has significantly boosted South Korea's trade with its Asian neighbors.

\section{References}

Chung, D. (1995) The Image of South Korea. Tokyo: Chuko Shinsho.

Dator, J. and Y. Seo (2004) 'Korea as the Wave of a Future: The Emerging Dream Society of Icons and Aesthetic Experience', Journal of Futures Studies 9(1): 31-44.

Demick, B. (2005) 'South Korean Actor Drives up Heart Rates and Sales in Japan: The Star of a Popular Soap Opera Has Become a One-Man Franchise That's Worth Billions', Los Angeles Times 2 November: A4.

Dudden, A. (2005) Japan's Colonization of Korea: Discourse and Power. Honolulu: University of Hawaii Press. 
Endo, F. and A. Matsumoto (2004) 'Currents: TV Dramas Melt Hearts, Thaw Japan-ROK Relations', The Daily Yomiuri 5 December: 1.

Hirama, Y. and Y. Sugita (2003) Kitachosen wo meguru hokutou asia no kokusaikankei to nihon [The International Relations in Northeast Asia Surrounding North Korea and Japan]. Tokyo: Akashi shoten.

Kim, D. (2006) 'Transcending Borders: Korean Soap Opera, Winter Sonata, Effects on Japanese Middle-Aged Women', paper presented to the 56th annual convention of the International Communication Association, Dresden, Germany, June.

Murakami, M. (2004) 'Middle-Aged Love Affair', South China Morning Post 24 April: 15.

Oberdorfer, D. (2001) The Two Koreas: A Contemporary History. New York: Basic Books.

Onishi, N. (2004) 'Korean Star Captures Fancy of Japan's Women', International Herald Tribune 16 December: A1.

Onishi, N. (2005a) 'Roll Over, Godzilla: Korean Rules', The New York Times 28 June: A3.

Onishi, N. (2005b) 'Ugly Images of Asian Rivals Become Best Sellers in Japan', The New York Times 19 November: A1.

Patton, M.Q. (2002) Qualitative Research and Evaluation Methods, 3rd edn. Thousand Oaks, CA: Sage.

Penn, W. (2004) 'Televiews: S. Korea Scores Another Winner', The Daily Yomiuri 7 October: 19.

Seo, J.-E. (2005) 'Pop Culture Makes Korea Shine in Asia', Joong Ang Daily 20 October: 1.

Singhal, A. and K. Udornpim (1997) 'Cultural Shareability, Archetypes and Television Soaps: "Oshindrome" in Thailand', Gazette 59: 171-88.

'To Keep "Hallyu" Going' (2005) The Korea Herald 12 January: 6.

'Travel Agencies Cashing in on Weepy Melodramas' (2004) The Daily Yomiuri 10 November: 4.

Tsukahara, M. (2004) 'Popularity of South Korean Dramas Surges in Addition to the Huge Hit Drama Winter Sonata on its Terrestrial Network, NHK', The Daily Yomiuri 3 June: 13.

Udornpim, K. and A. Singhal (1999) 'Oshin, a Pro-Social Media Role-Model, in Thailand', Keio Communication Review 21: 3-21.

Victoria, J. (2005) 'How Korea Became Cool', New Statesman 7 March: 16.

'War Torn: Soap Opera Resonates with Elderly Japanese Women' (2004) Wall Street Journal 15 September: 3A.

Wiseman, P. (2004) 'Korean Romantic Hero Holds Japan in Thrall: Frenzy over Heartthrob Symbolizes Changing Relations between Peoples', USA Today 10 December: 13A.

Yong-sung, L. (2005) 'Is It All Over Already? Gloomy Signs Overshadow Rosy Statistics of "Hallyu"', The Korea Herald 11 July: 16.

Yoshida, S. (2004) 'Korean, Chinese Languages Expanding in High Schools', The Daily Yomiuri 23 November: 16 .

Toru Hanaki is Lecturer of Communication Studies in the Faculty of Foreign Studies at Nanzan University. His research interests focus on communication and culture, and communication in everyday life.

Address Faculty of Foreign Studies, Nanzan University, 18 Yamazato-cho, Showa-ku, Nagoya 466-8673 Japan. [email: th139902@ohio.edu]

Arvind Singhal is Professor of Communication Studies at Ohio University and from Fall 2007 will be the Samuel Shirley and Edna Holt Marston Professor of Communication and Senior Research Fellow, Sam Donaldson Center for Communication Studies, University of Texas. He is the author/editor of eight books, including Communications of Innovations: A Journey with Ev Rogers (London: Sage, 2006), Organizing for Social Change (London: Sage, 2006), and Entertainment-Education and Social Change: History, Research, and Practice (Mahwah, NJ: Lawrence Erlbaum, 2004).

Address School of Communication Studies, Lasher Hall, Ohio University, Athens, OH 45701, USA. [email: singha/@ohio.edu] 
Min Wha Han is a doctoral student in the School of Communication Studies at Ohio University. Her research interests are in fields of rhetoric and cultural studies, historiography and postcolonial studies.

Address School of Communication Studies, Lasher Hall, Ohio University, Athens, OH 45701, USA. [email: mh947404@ohio.edu]

Do Kyun Kim is a doctoral student in the School of Communication Studies at Ohio University. His research and teaching interests include diffusion of innovations, social networks, media studies and health communication.

Address School of Communication Studies, Lasher Hall, Ohio University, Athens, OH 45701, USA. [email: dk444693@ohio.edu]

Ketan Chitnis is Programme Communication Officer, UNICEF New York. His professional expertise and research interests are in communication and international development.

Address 3 UN Plaza, New York, NY 10017, USA. [email: kchitnis@unicef.org] 